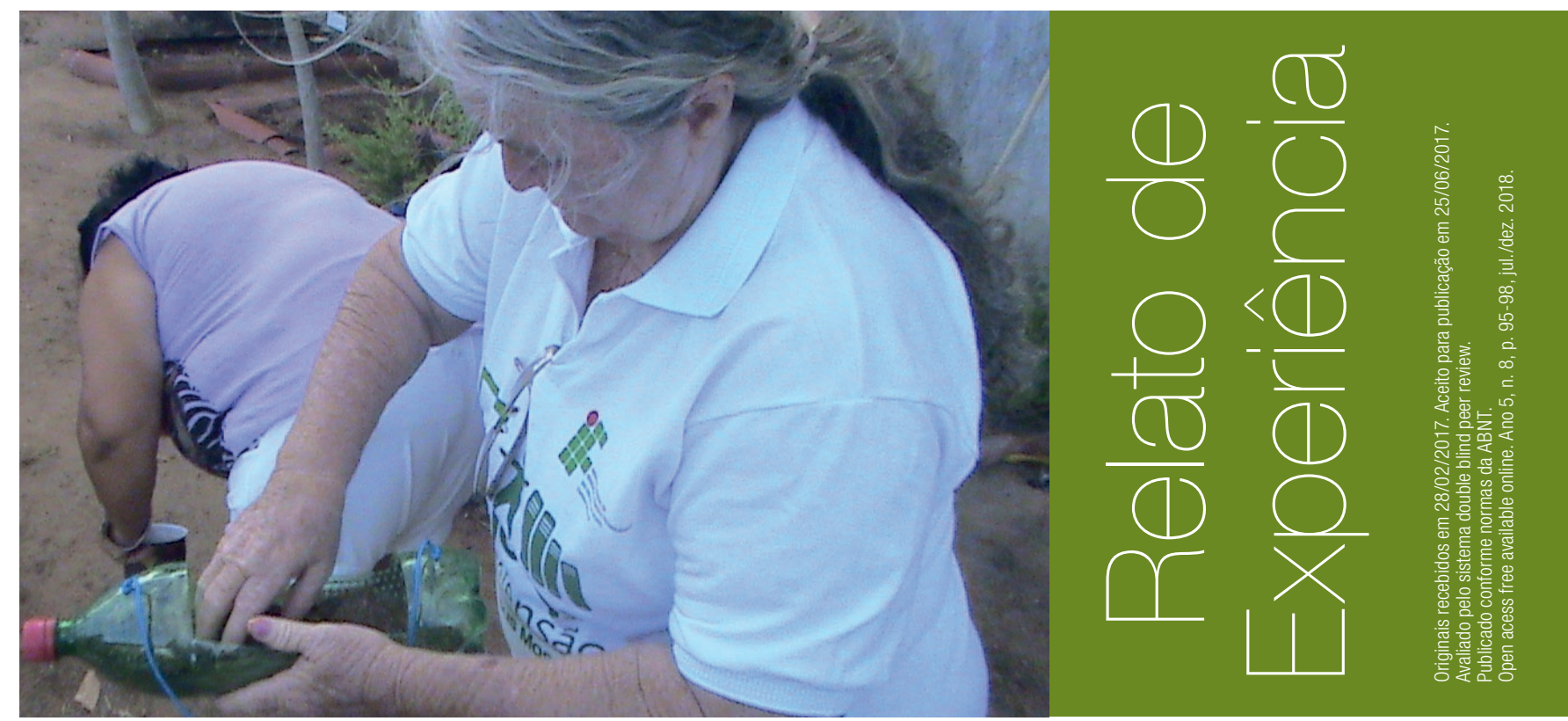

\title{
Plantando saúde: disseminando técnicas de compostagem e horta caseira em Mossoró/RN
}

José Araujo Amaral ${ }^{1}$ - jose.amaral@ifrn.edu.br

Helen Flavia de Lima² - helenflavia@uern.br

\section{RESUMO}

No câmpus Mossoró do Instituto Federal do Rio Grande do Norte (IFRN), reaproveitamos o lixo orgânico escolar para produção de adubo, criamos uma horta e escolhemos um suporte físico para plantio em pequenos espaços, além de um modelo de composteira doméstica. Como ação extensionista, divulgamos, por minicursos, as técnicas de compostagem e plantio caseiro para 52 donas de casa de Mossoró/RN.

\section{PALAVRAS-CHAVE}

Cultivo doméstico. Resíduos orgânicos. Horta escolar.

\section{ABSTRACT}

On Federal Institute of Rio Grande do Norte, câmpus Mossoró, organic waste is reused as fertilizer. We have stablished a vegetable garden, elected physical support solutions for gardening in small spaces and for composting at home. As an extension, we have shared these techniques, thru mini-courses, with fifty-two housewifes living in Mossoró/RN.

\section{KEYWORDS}

Domestic cultivation. Organic waste. School vegetable garden.

\footnotetext{
1 Biólogo, professor de Biologia no IFRN/Mossoró e doutor em Biotecnologia.

2 Historiadora, professora auxiliar do Departamento de Gestão ambiental/ UERN e mestre em História
} 


\section{Introdução}

A geração de resíduos sólidos é um dos grandes problemas ambientais nos nossos dias (CASTR0, 2006). Aproximadamente 39\% de todo resíduo que chega aos lixões ou aterros sanitários todos os dias nas grandes cidades é composto por matéria orgânica proveniente de restos de alimentos (CARVALHO JUNIOR, 2006). Esse material gera grandes volumes de chorume, o que pode contaminar os lençóis freáticos.

Uma das formas de reduzir esse impacto ambiental seria investir em compostagem, processo que consiste na transformação dessa matéria orgânica em adubo, que pode servir como aporte para suplementação nutricional no cultivo de hortaliças e legumes de forma ecologicamente correta (PEIXOTO, 2005).

0 incentivo ao estabelecimento de uma horta caseira, ou seja, uma horta mantida no espaço doméstico, quintal, área de serviço etc, pode ser uma alternativa para promoção da educação ambiental e da segurança alimentar, pois permite a obtenção de alimentos sem 0 uso de agrotóxicos assim como valoriza 0 consumo de hortaliças e verduras, fontes de nutrientes relacionados a uma alimentação saudável (LUCON; CHAVES, 2004).

0 trabalho que foi desenvolvido teve como objetivos: 0 estabelecimento de uma horta escolar, o domínio das técnicas de compostagem e de montagem de pequenos suportes para cultivo, para que pudéssemos, ao final do processo, propor uma ação extensionista capaz de estimular donas de casa a estabelecerem suas próprias composteiras caseiras (sistemas de compostagem mantidos em casa) e a cultivar hortaliças em suportes físicos para pequenos espaços.

\section{Método}

0 trabalho iniciou com o aproveitamento dos resíduos da merenda escolar para compostagem em tanque, conforme descreve Peixoto (2005). 0 adubo gerado foi utilizado na montagem da horta escolar, de acordo com a metodologia descrita em Lucon e Chaves (2005). Preparamos o terreno cedido pela escola e foi realizado um estudo com plantios diversos (alface, rúcula, salsinha etc) para verificar as culturas mais adaptadas às nossas condições ambientais.

Estudamos alguns suportes físicos para escolhermos o mais adequado como modelo de suporte para cultivo caseiro, ou seja, pequena horta em pequeno espaço. 0 suporte selecionado foi 0 de garrafa PET de dois litros por conta da facilidade em encontrar e manipular o material. Além disso, estabelecemos um modelo de composteira caseira (sistema de compostagem doméstico) para 0 aproveitamento de sobras orgânicas domésticas, a partir das informações obtidas em Peixoto e Fernandes (2016).

Montamos um minicurso para divulgar as técnicas desenvolvidas e incentivar donas de casa de Mossoró a estabelecerem composteiras e cultivos de hortaliças em suas casas. 0 minicurso foi organizado em outubro de 2015, pelos autores desse artigo e por duas alunas bolsistas, e ministrado em novembro e dezembro desse mesmo ano para duas turmas de 26 donas de casa convidadas que participavam de um curso de extensão em informática no IFRN/Mossoró.

\section{Resultados}

A partir da coleta dos resíduos da merenda escolar, geramos $40 \mathrm{~kg}$ de adubo orgânico para 0 uso na horta escolar, ou seja, na horta mantida na escola como horta matriz (Figuras 1a e 1b). Com o material, preparamos o solo e estabelecemos a horta; escolhemos as hortaliças que se adaptariam melhor às condições de solo e adubagem e quais poderiam ser utilizadas nos cultivos em suportes físicos para pequenos espaços (Figura 2a). As hortaliças selecionadas foram rúcula e alface, pois apresentaram rápido crescimento e porque as mudas se adaptaram ao suporte para pequeno espaço. 


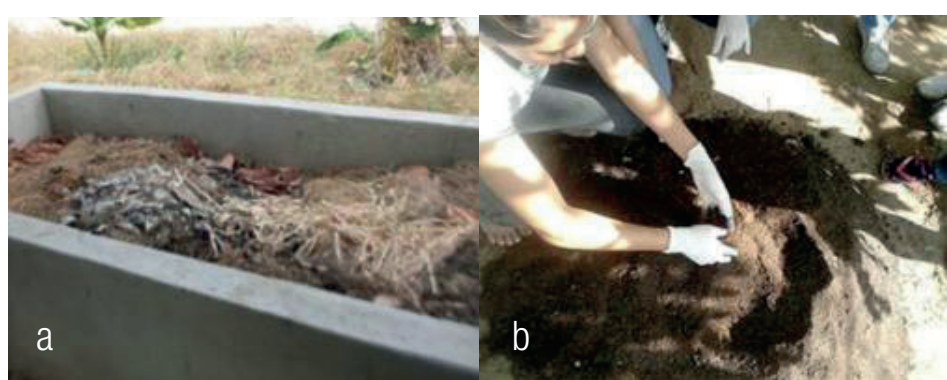

Figura 1: a) Detalhe de um dos tanques

de compostagem utilizados para a

produção de adubo orgânico a partir

das sobras da merenda escolar;

b) aspecto do composto (adubo)

produzido sendo manipulado.

Fonte: Arquivo dos autores.

Após o plantio, a equipe se dedicou a planejar um modelo de composteira que pudesse ser replicado nas casas das participantes do projeto. Experimentamos alguns suportes e optamos, ao final, por um composto por um balde furado e recipiente reutilizado (balde grande de margarina), pois são recipientes de fácil aquisição pelo público-alvo do minicurso. Nesse recipiente, foram colocados restos de material orgânico (restos de folhas ou papel) e areia.

Depois desse processo, foram colocados os resíduos orgânicos (Figura 2b) e cobriu-se o material com areia e restos de folhas secas ou papel. À medida que se colocava novo material orgânico realizava-se 0 mesmo procedimento de cobertura com restos de folhas secas ou papel. Após uma semana da realização desse processo, foi feita uma mistura de todo material depositado no balde para a aeração. Enquanto ocorria a decomposição da matéria orgânica, também era feita a deposição do chorume no coletor colocado logo abaixo do balde de compostagem (Figura 2c).

A última etapa da pesquisa compreendeu a divulgação dessas técnicas, por meio de minicursos, para a comunidade de Mossoró. Realizamos dois minicursos teórico-práticos nas dependências do próprio IFRN/Mossoró em que foram explicadas as bases teóricas do trabalho, com ênfase na discussão sobre a problemática ambiental decorrente da produção de lixo orgânico, e falouse sobre a possibilidade do uso desse lixo orgânico como adubo para pequenas hortas. Ação essa que pode contribuir para o aumento no consumo de alimentos sem agrotóxicos.

Durante esse encontro, foi mostrado o funcionamento de uma composteira feita com material reaproveitado, conforme mostramos nas figuras 2b e 2c. Após conhecerem esses processos, os participantes ajudaram a preparar o suporte para cultivo de plantas em pequeno espaço, feito com garrafa PET cortada, terra e adubo (Figura 2a) para ser utilizado em uma horta na escola.

Após a aula, os participantes do minicurso foram para a horta da escola. Eles tiveram o desafio de (Figura 3b) montar um canteiro e de plantar mudas em um suporte de garrafa PET (Figura 3c).
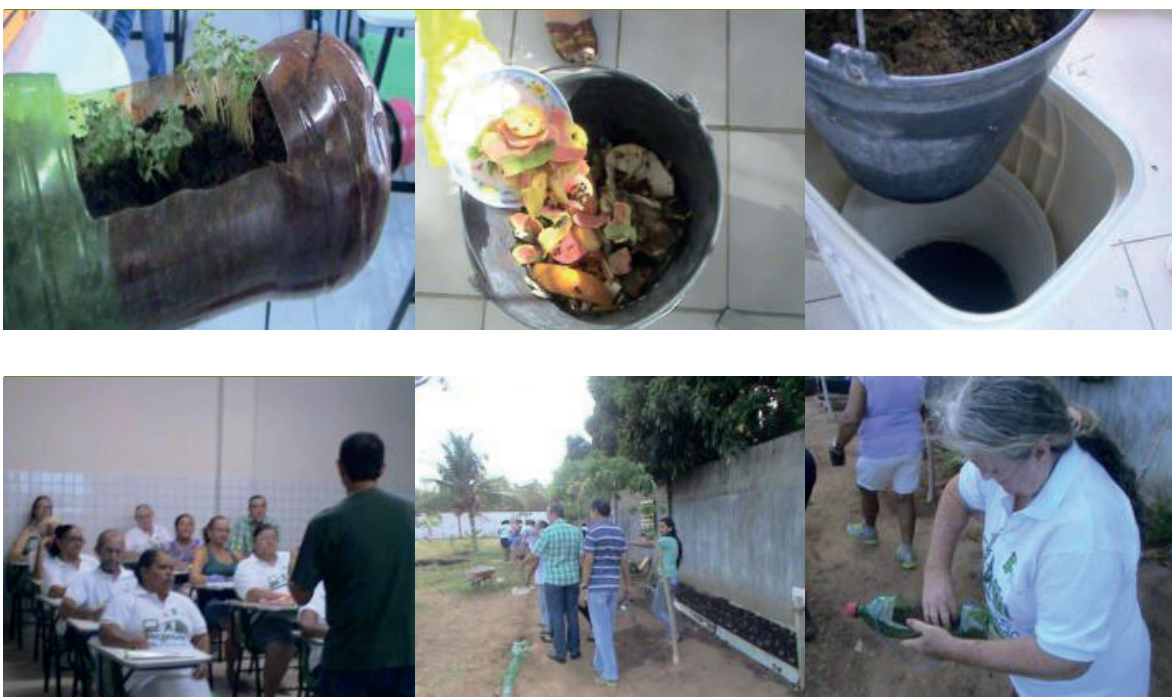

Figura 3: Minicurso teóricoprático de compostagem e horta caseira no IFRN/Mossoró.

Fonte: Arquivo dos autores.
Figura 2: a) Detalhe do modelo de suporte para horta feito a partir de garrafa PET; b e c) Detalhes da montagem da composteira utilizando balde velho furado e pote plástico de margarina de padaria industrial como coletor do chorume.

Fonte: Arquivo dos autores.

Após o plantio, os participantes avaliaram o minicurso. Eles ressaltaram a importância e eficiência da ação extensionista para esclarecer a relação entre lixo orgânico e poluição ambiental. Muitos mostraram-se entusiasmados ao saber que cada pessoa pode contribuir para a diminuição da produção de lixo ao mesmo tempo em que pode produzir alimento sem agrotóxicos utilizando adubo produzido a partir de resíduo orgânico. 
Como pontos a serem melhorados em nosso trabalho destacamos: a proposição de um modelo de compostagem caseira que possa ser feito de forma mais rápida, já que o processo utilizado leva 60 dias para se completar, a diversificação das hortaliças cultivadas e a ampliação da oferta dos minicursos. Para tanto, temos a intenção de propor a oferta de novos cursos de compostagem em eventos científicos voltados à comunidade externa, tais como exposições científicas e semanas do meio ambiente.

\section{Referências}

CARVALHO JUNIOR, Francisco Humberto. Resíduos sólidos urbanos: coleta e destino final. Disponível em: <http://www.cchla.ufrn.br/geoesp/arquivos/sergio/pdf>. Acesso em: 15 jul. 2017.

CASTRO, Maurício Barros de. A reciclagem de alumínio no Brasil. Rio de Janeiro: Editora Desiderata, 2006.

LUCON, Cleusa Maria Mantovanello; CHAVES, Alexandre Levi Rodrigues. Horta Orgânica. Biológico, São Paulo, v.66, n.1/2, p.59-62, jan./dez. 2004.

PEIXOTO, R. T. dos G. Compostagem: princípios, práticas e perspectivas em sistemas orgânicos de produção. In: Agroecologia: princípios e técnicas para uma agricultura orgânica sustentável. 1ª ed. Brasília, DF: Embrapa Informação Tecnológica, 2005.

PEIXOTO, Alan Amorim; FERNANDES, Juliana Gonçalves. Utilização da técnica de compostagem: uma proposta para destinação final dos resíduos orgânicos gerados em um restaurante universitário. Disponível em: <www.aedb.br/seget/arquivos/artigos16/8524288. pdf>. Acesso em: 15 jul. 2017. 